\title{
SONOGRAPHIC ANTENATAL DIAGNOSIS OF ACARDIA ACEPHALUS
}

\author{
Jack M. Gibson, M.D., Thomas J. Cusack, M.D., Peter J. Couri, M.D., \\ Muhammed A. A. Khan, M.D., and Michael S. Cardwell, M.D. \\ From the Department of OB-GYN, Peoria School of Medicine, Peoria, Illinois 61637
}

The sonographic criteria for prenatal diagnosis of Acardia Acephalus are presented. These criteria are readily identifiable and should lead to the diagnosis of Acardia Acephalus in every case.

DOI: http://dx.doi.org/10.5915/15-3-12411

\section{Abstract}

Two cases of Acardia Acephalus are presented. One case was diagnosed prenatally by compound and real-time sonography. The criteria for prenatal diagnosis is discussed as well as a review of the current literature of acardia. The presence of twins, which continue to grow despite the lack of fetal heart motion in one of the twins, is a readilyidentifiable pathognomonic sonographic finding for this syndrome.

Acardia Acephalus is a rare condition which occurs only in monozygotic twins or triplet pregnancies. Its incidence has been reported as approximately one in 35,000 deliveries or less than $1 \%$ of all identical twin pregnancies. The abnormal twin lacks all cephalic structures and lacks many of the normal thoracic and upper extremity structures. The etiology is unknown, but other investigators have reported chromosomal abnormalities as a possible cause. ${ }^{1}$ In order for the acardiatic twin to survive, a twin-to-twin transfusion syndrome must be present.

Numerous studies have had retrospective diagnoses of the acardia syndrome, ${ }^{1,2,3}$ however, we report a case of prenatal diagnosis by ultrasound scanning. Also included in this report is a previous case of acardia with retrospective sonographic findings at our institution five years ago. These findings are characteristic and should be recognized sonographically.

\section{Case Number One}

D.K. a 19-year-old white married female gravida 2 , para 2, ab O, sought prenatal care at 32 weeks gestation. During this pregnancy, due to being large for dates and clinically suspected hydramnios, she had a sonogram at approximately 36 weeks gestation which revealed moderate hydramnios, a normal fetus in cephalic presentation with a biparietal diameter of $88 \mathrm{~mm}$. consistent with 36.5 week gestation. A second intrauterine mass was identified which was irregular in shape and without identifiable fetal parts (Fig. 1). It was felt at that time that the mass was a degenerating fetus, however, other intrauterine masses could not be ex-

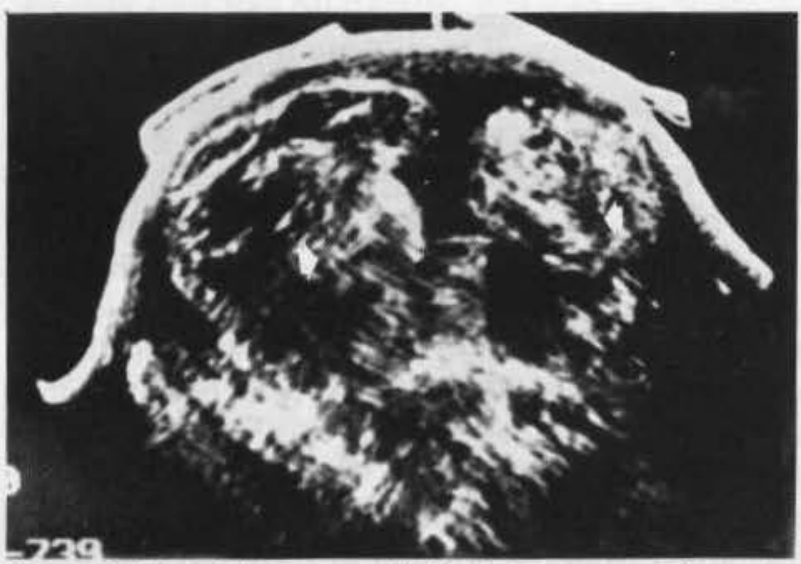

Figure 1: The white arrow at left shows an amorphous in. trauterine mass and at the right a white arrow points to a live fetus which is intrauterine.

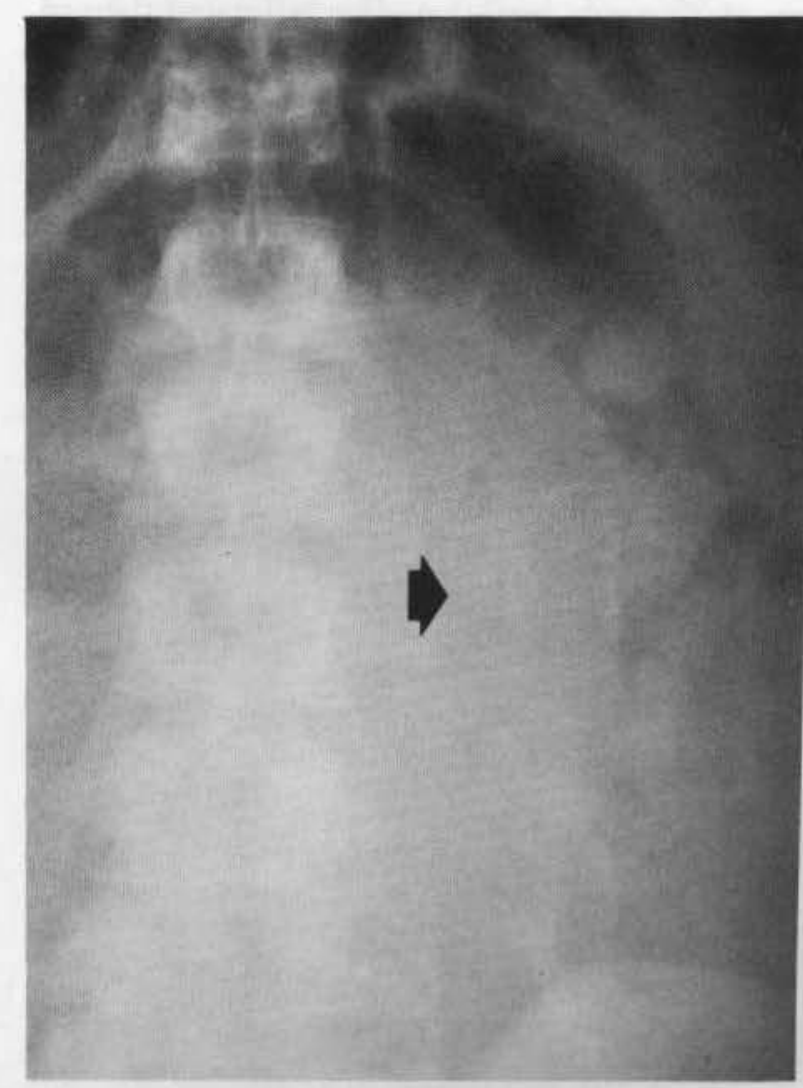

Figure 2: An abdominal roentgenogram showing a fetus, breech position, without ossified skull. 
cluded. An abdominal roentgenogram (Fig. 2) was taken at that time and confirmed the presence of a normal fetus in cephalic presentation and a second anomalus fetus without an ossified calvarium nor upper extremities. At that time no fetal heart motion nor fetal movements were seen on the anomalus fetus by real-time scanning.

The patient subsequently went into spontaneous labor at 38.5 weeks gestation and by vaginal delivery delivered a live-born female infant in cephalic presentation with Apgar Scores of 8 and 10 through a midline episiotomy. The anomalus twin delivered by breech presentation (Fig. 3). Both infants were female. The pathological examination of the anomalus twin and the placenta revealed that: (1) the anomalus twin was an acardia acephalic fetus; (2) amelia, upper extremity was present; (3) phocomelia of the left lower extremity with absence of the 4th and 5th toes. Pathological examination of the placenta showed it to be a monochorionic diamniotic type. The umbilical cord was normal consisting of two arteries and one vein. Chromosomal analysis at that time was not performed. The mother and the normal female infant were discharged from the hospital in three days.

\section{Case Number Two}

M.F. Gravida 5, para 3, ab 1, sought prenatal care at 20 weeks gestation. Her estimated date of confinement was December 29, 1981. Her prenatal course had been complicated by urinary tract infection in the second trimester; she had smoked one pack of eigarettes per day and had had a weight gain of 24 pounds at 30 weeks gestation.

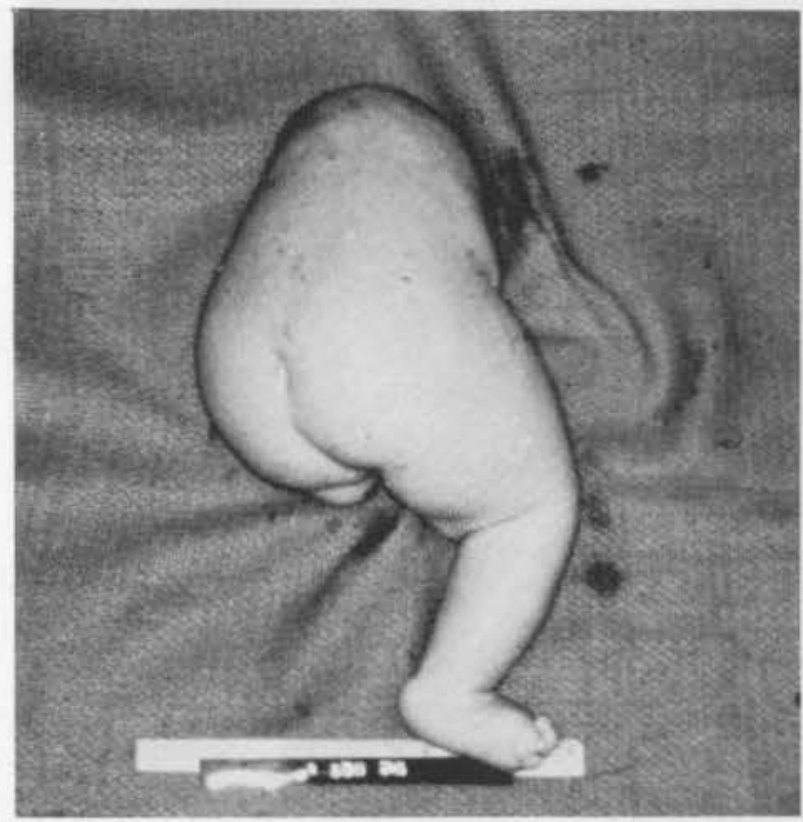

Figure 3: Gross photograph of acardia twin - case number one.
She had been referred for sonographic examination at 28 weeks gestation with suspected hydramnios. On initial sonographic examination, using static and real-time techniques, a live fetus with a biparietal diameter consistent with 28 weeks gestation and a relative bradycardia were observed. Also encountered was a mass found to be occupying the fundal portion of the uterus. The mass was approximately $12 \mathrm{~cm}$. at its largest diameter having multiple cystic areas in the uppermost part and having two extremities in the lower-most part. No fetal heart motion or other fetal movement was recognized.

A repeat sonogram two weeks later found that the live fetus was growing at a normal rate. Moderate hydramnios, however, still persisted. The amorphous mass which was encountered on a previous sonogram was studied in further detail (Fig. 4 \& 5).

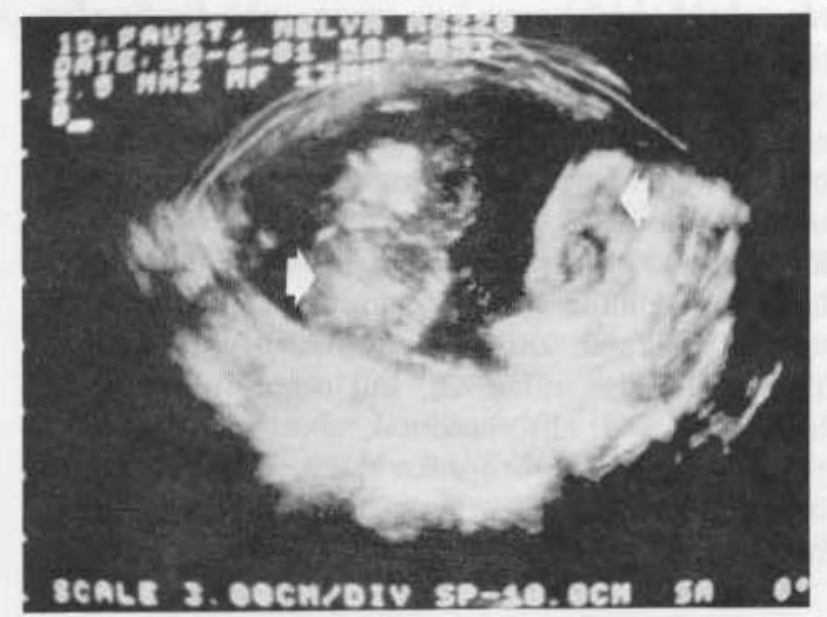

Figure 4: White arrow at left showing edematous lower ex. tremities. The white arrow at right showing normal twin's thoracic area.case number two.

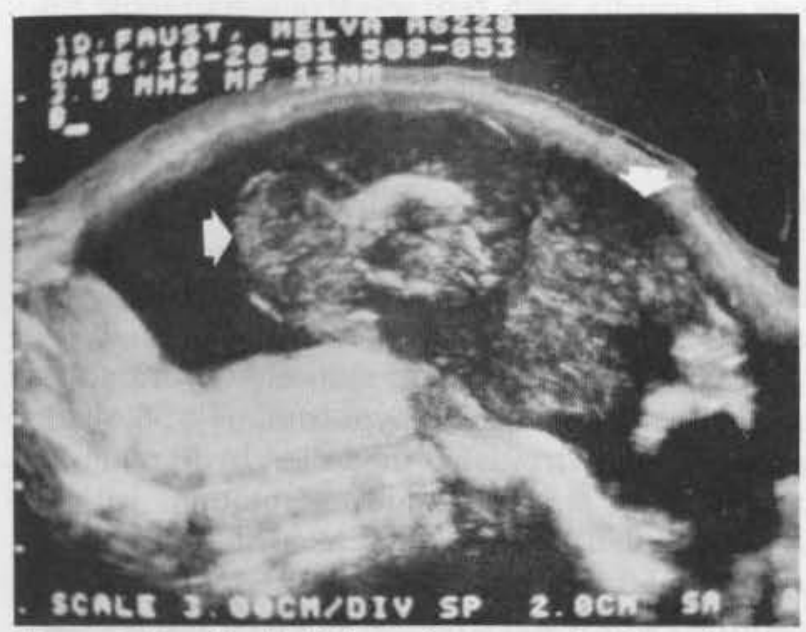

Figure 5: Longitudinal view of case number two showing acephalic monster, breech presentation. Arrow at left is the superior pole. The right arrow shows the edematous lower extremities. 


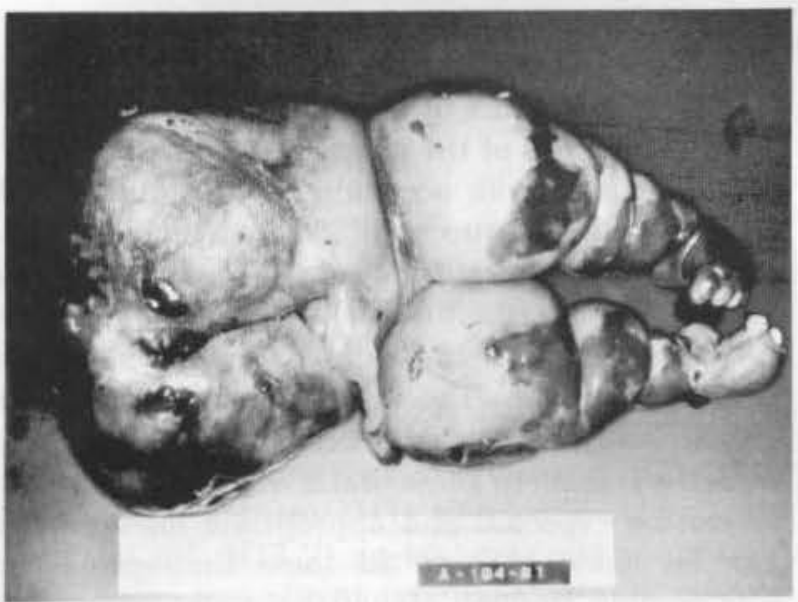

Figure 6: Gross photograph of case number two.

The mass was in a breech presentation with ossified lower limbs, lumbosacral vertebrae, and some thoracic vertebrae and ribs. No cephalic or upper limb structures could be identified nor any fetal heart motion seen. Numerous cystic areas were again seen in the upper portion of the anomalous fetus. The upper portion of the mass now measured $14 \mathrm{~cm}$. An abdominal roentgenogram examination was obtained and correlated with sonographic findings. Prenatal diagnosis of acardia acephalus was made at 30 weeks gestation based upon the above sonographic findings. Ten days later the patient went into spontaneous labor with ruptured membranes and delivered a live born female infant with Apgar Scores of 8 and 9, birth weight 2 lbs. 15 ounces by normal spontaneous vaginal delivery. A second amniotic sac was ruptured at the time of delivery releasing approximately $1300 \mathrm{cc}$ 's of clear amniotic fluid. The second twin was in a double footling presentation and was delivered vaginally. The birth weight of the female acardia acephalic

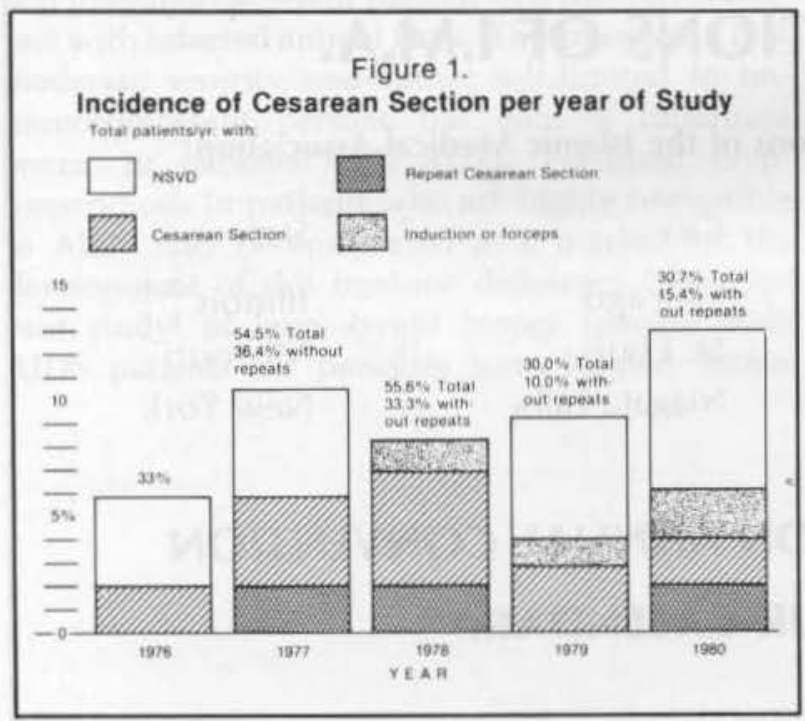

twin was 4 lbs. 7 ounces. The placenta delivered spontaneously. The umbilical cords were examined at the time of delivery and both were found to contain two arteries and one vein. The umbilical cords ran next to one another and coursed down a common membrane and appeared to insert together on the placenta. The acardiac twin upon gross examination (Fig. 6) was severely hydropic lacking any cephalic or upper limb structures. The lower extremities were anomalus in that the feet contained only four toes bilaterally. Autopsy was performed and yielded markedly rudimentary abdominal viscera with absence of any recognizable structures above the diaphragm. Final pathological diagnosis correlated with our prenatal diagnosis of an acardia acephalic fetus.

\section{Discussion}

Sonography is now being used widely for prenatal evaluation, for routine obstetrical screening, and for suspected in utero anomalies. ${ }^{4}$ Many anomalies have been diagnosed prenatally and many others have had retrospective sonographic findings after delivery.

The sonographic criteria for prenatal diagnosis of acardia have been suggested by many other authors to include absence of fetal head, absence of fetal heart motion, absence of fetal movement, and hydramnios.' We have added to that list multiple cystic sonolusant areas in a cephalic portion of the anomalus twin and a relative bradycardia of the normal twin. In our two cases and in other cases described, $1,2,38$ marked edema of the acephalic acardiatic twin is common and the anomalus twin usually occupies the fundal portion of the uterus. The acardia monster can be classified into many types as others have been described. ${ }^{5}$ In our cases the presenting type has been acardia acephalus. The acardia acephalus lack any thoracic or cardiac structures and contain rudimentary abdominal viscera. $^{7}$

In review of the literature there have been over 100 cases of the acardias described. $\mathrm{Hempel}^{7}$ in 1850 pointed out that for the acardias to persist there must be vascular placental anastomoses between the acardiac and his twin, thus constituting a twin-to-twin transfusion syndrome. ${ }^{6} \mathrm{Hydramnios}$ is present in the majority of these cases, however, the etiology has not been defined. The placenta must always be a monochorionic, however, it can be diamniotic. The acardiac monster and his twin have always been of the same sex, however, chromosomal studies done by others have revealed that the acardia twin usually has XO karyotype. The karyotypes of the normal twins have apparently normal karyotypes. There have been two 
pathological theories that have been discussed at great length. One theory holds that the acardiac fetus never develops a heart and is kept alive by the twin's heart from early embryonic time. There is a second theory, however, that states that the acardiac was originally a normal twin whose cardiac structures degenerated later during fetal life.

Acardia acephalus is the most common type with over 100 cases reported since the 16 th century. They are headless and lack thoracic organs; their ribs and vertebra can be present. The upper extremities are usually absent or defective. The abdominal organs are rudimentary but the genitalia are usually fairly well developed.

Other types of acardias are the acardias acorneus and acardia amorphous. The first is a monster with a head without a body and is attached to the placenta by an umbilical cord. The latter is usually a shapeless mass covered by skin and some hair with rudimentary organs which are sometimes recognizable.

\section{Summary}

Prenatal diagnosis of acardia acephalus can be obtained by conventional and real-time sonography in utero.

The pathognomonic features are:

1. Twin pregnancy, one normal twin, one anomalous twin.

2. Absence of fetal head in the anomalous twin.

3. Absence of fetal heart motion in the anomalous twin.

4. Evidence of growth of the anomalous twin.

Associated findings may include:

1. Appearance of hydramnios.
2. Multiple cystic areas in the cephalic portion of the anomalous twin.

3. Bradycardia of the normal twin.

4. Hydrops of the anomalous twin.

Although acardia acephalus is a rare condition being found only once in 35,000 deliveries, the appearance of an intrauterine mass accompanied by a normal intrauterine pregnancy which fulfills these criteria should lead one to the prenatal diagnosis of acardia acephalus. The value in being able to make an early diagnosis enables both the parent and the obstetrical team to know that a serious fetal anomaly can be expected and appropriate management can be made in view of these findings. These sonographic findings should be easily recognized and are characteristic findings of acardia acephalus and prenatal diagnosis should be made in every case where sonography is utilized.

\section{References}

1. Deacon, J.S., et al; Investigation of Acephalus. Am. J. Med. Genetics 5:85-99 1980.

2. Lehr, C., et al: Rare Occurrence of a Holoacardious Acephalic Monster: Sonographic and Pathologic Findings. J. Clin. Ultrasound 6:259, 1978.

3. Napolitani, F.D. et al; The Acardiac Monster, Am. J. Obst. \& Gynec. 80: 582-587, 1960.

4. Stephenson, S.R., et al: Prenatal Diagnosis-A compilation of Diagnosed Conditions. Am. J. Obst. \& Gynec, 141: 319, 1981.

5. Warkany, J.: Congenital Malformations: 50-473-4.

6. Wittman, B.K. et al: Antenatal Diagnosis of Twin Transfusion Syndrome by Ultrasound. Obst. \& Gynec. 58-1-123-127, 1981.

7. Hempel: De Monstris Acephalis, Dissert. Hafniar, 1850. Cited by Schwalbe, E. (ed.), in Die Morphologie der Missbildungen des Menschen und der Tiere (Jena: Gustau Fischer, 1907), Vol. 2, Chap. X.

8. Mack. L.A., et al, Antenatal Ultrasonic Evaluation of Acardiac Monsters. J. Ultrasound Med 1:13-18, Jan-Feb. 1982. 